\title{
Mammography Quality in Turkey: Auditors' Report on a Nationwide
}

\section{Survey}

\author{
Arzu Ozsoy, ${ }^{1,}$ Erkin Aribal, ${ }^{2}$ Levent Araz, ${ }^{1}$ Merter Bora Erdogdu, ${ }^{3}$ Aydin Sari, ${ }^{3}$ Irfan Sencan, ${ }^{3}$ and Nevra
}

Elmas ${ }^{4}$

${ }^{1}$ Department of Radiology, Ankara Numune Training and Research Hospital, Ankara, Turkey

${ }^{2}$ Department of Radiology, Marmara University Faculty of Medicine, Istanbul, Turkey

${ }^{3}$ Ministry of Health of Turkey, Ankara, Turkey

${ }^{4}$ Department of Radiology, Ege University Faculty of Medicine, Izmir, Turkey

"Corresponding author: Arzu Ozsoy, Department of Radiology, Ankara Numune Training and Research Hospital, Ankara, Turkey. Tel: +90-3125954863, Fax: +90-3124953475, E-mail: arzu.ozsoy@hotmail.com

Received 2015 September 18; Revised 2015 October 27; Accepted 2015 December 22.

\begin{abstract}
Objectives: To evaluate the mammography image and reporting quality in Turkey.

Materials and Methods: One hundred sixty five units which provide mammography examination services were included in the audit. Samples of mammographic examinations conducted between July 1st and December 31st, 2012 were evaluated. Auditors completed web-based evaluation forms, including quality parameters and descriptive statistics on the patients and institutions.

Results: Nine hundred eighty eight mammography examinations were evaluated; $47.34 \%$ of them used mammography machines less than 5 years old. Most of the older machines (10 years old or more) were grouped in private hospitals (22.1\%) and university hospitals (21\%). Mammographic image quality evaluation showed 56.1\% non-compliance with the standard parameters. Private institutions showed the highest failure rates $(\mathrm{P}<0.001)$, and low-quality images mostly $(42.2 \%)$ resulted from mistakes in positioning. In $32 \%$ of the mammography reports, some mandatory information was incomplete. The reports were deemed inadequate in $59.2 \%$ of the cases.

Conclusion: The audit showed significant deficiencies in terms of quality. We suggest investing more time and effort to train both radiologists and radiologic technicians to implement image and report quality standards in their units. Moreover, our study emphasized the importance of the accreditation of the units.
\end{abstract}

Keywords: Mammography, Screening, Turkey

\section{Background}

Mammography screening is currently the most effective method for the early detection of breast cancer $(1,2)$, but high mammography image quality is crucial for the success of a breast screening program $(3,4)$. Quality standards for mammography have been established in various countries, and breast imaging units are accredited and monitored strictly (5-10). In Turkey, breast cancer screening standards were defined by the Turkish Radiology Society (11). Although there is no national screening program in Turkey, voluntary screening is done widely and screening costs are reimbursed for patients between ages 40 and 70.

\section{Objectives}

The aim of this study was to assess the quality of mammographic examinations and reports in Ministry of Health hospitals, university hospitals, and private breast imaging units in Turkey. This study was performed with the cooperation of the Ministry of Health (MOH).

\section{Materials and Methods}

Mammography units from all across the country were included in the audit: of the 745 institutions which provide mammography examinations, 165 units were evaluated. Eighty two were from $\mathrm{MOH}$ hospitals, 47 from private hospitals, and 36 from university hospitals. Three hospitals from Ankara, Istanbul, and Izmir were included, along with at least one hospital from each province; all the included hospitals performed at least 10 mammographic examinations per day. A stratified sampling method was used to determine which hospitals to include in the study. In every hospital a supervisor was appointed as the coordinator physician, to organize the data necessary for the study. The number of patients to be included in the study was determined in proportion to the unit's number of monthly mammograms. Specific mammograms were se- 
lected for auditing by the "Simple Random Sampling" technique.

A scientific audit commission was assembled, consisting of two radiologists (EA, LA) from the breast study group of the Turkish radiology society, one statistician (MBE), and one coordinator (AS) from the ministry of health. The survey forms were created by this committee. All forms were web-based and had two sections: the first section gathered data on the hospital, equipment, and descriptive statistics on the patients, while the second section included the auditing measures. The coordinating physicians of the selected institutions completed the first section. Coordinators also collected mammography images and reports and delivered them to the provincial health directorates, who distributed them to the auditors. Furthermore, 34 auditors were selected amongst the radiologists in the surveyed hospitals who were experienced with breast imaging. These auditors completed the second section of the survey.

To assess the completeness of mandatory information in the mammographic reports, the following data was tracked: patient information, the name of the medical center where the examination was performed, information about the reporting doctor, the name of the procedure, and the date of the examination. To assess the mammographic report quality, the following elements in the reports were investigated: the reason for the examination, the definition of the positions, the use of breast imaging reporting and data system (BI-RADS) classification and expression of the findings, the final results, and the recommendations.

Individual mammogram images were also evaluated for mammographic image quality, based on positioning, compression, contrast, density, artifacts, and labeling. The auditors were free to report more than one deficiency. The American college of radiology (ACR) and Turkish radiologic society (TRD) recommendations were used for image analysis (11,12). All mammograms were evaluated using soft copies if the images were digital and hard copies if they were analog. All the facilities were also asked to send daily phantom images. The presence and also the conformity of the daily phantom images were recorded. Statistical analyses were performed using SPSS version 15.0 (SPSS Inc., Chicago, Il, USA). To test the significance of the relationship between the categorical variables, chi-square test, Pearson's chi-square test, and Fisher's Exact test were used. $P$ value $<0.05$ was accepted as significant.

\section{Results}

Totally 133,466 mammography examinations were performed between July 1-December 31, 2012, and 988 of them were evaluated in the study. Regarding age distribution, $4.5 \%$ of the patients were between 30 - 39 years of age, $40.8 \%$ were between 40 - 49, 36\% were between 50 - 59, and $13.4 \%$ were between 60 - 69 .

Among the mammography machines, $47.34 \%$ were new machines (less than 5 years old), $36.7 \%$ were 5 - 10 years old, and $16 \%$ were found to be 10 years or older (Table 1 ).

In the $\mathrm{MOH}$ hospitals, $66 \%$ of the machines were younger than 5 years; this proportion was $46.1 \%$ in the university hospitals and $47.7 \%$ in the private institutions (Table 1). Most of the older machines (10 years or more) were grouped in private hospitals (22.1\%) and university hospitals (21\%), but only $5.25 \%$ of the machines in MOH hospitals belonged to this group. The machine types were: $46.6 \%$ analog machines with computed radiography (CR) processing systems, $32 \%$ analog with analog developers, and $21.4 \%$ offered full field digital mammograms. The majority of the machines (80.3\%) were owned by the hospitals, and the other $19.7 \%$ were service procurements. Totally $91.4 \%$ of the university hospitals had their own machines, however this rate was $89.4 \%$ in private hospitals and $67.6 \%$ in the $\mathrm{MOH}$ hospitals. The mammograms were reported by registered doctors at the hospitals in $92.3 \%$ of cases, whereas $7.7 \%$ were reported by the procurement service.

The majority of the mammograms (74.8\%) were firsttime mammograms for that patient, while $25.2 \%$ of patients had previous mammographic examinations. The number of prior mammographic examinations was 1 in $61.7 \%$ of the patients, 2 in $20.4 \%, 3$ in $7.5 \%, 4$ in $4.5 \%$ and 5 or more in $5.9 \%$ of the patients. Among all patients, 39.3\% had completed another mammogram in the past year (Table 1). Among these patients, $64.8 \%$ referred to MOH hospitals, $32.6 \%$ referred to university hospitals, and $68.5 \%$ referred to private hospitals. Among the patients, $42.6 \%$ got a new mammogram for screening reasons.

Mammographic image quality results showed $56.1 \%$ non-compliance with the standards. There was a significant difference between institutions $(\mathrm{P}<0.001)$. The technical parameters were not in accordance with standards in $24.8 \%$ of the university, $57.6 \%$ of the $\mathrm{MOH}$, and $79.1 \%$ of the private hospitals. When the inappropriate mammographic images were evaluated, the deficiencies in the quality of the mammographic images mostly $(42.2 \%)$ resulted from mistakes in positioning, followed by failures in contrast and density (Table 2).

Daily phantom images were requested from each department, but only $2.6 \%$ of the departments sent a daily phantom image.

Sixty eight percent of the mammography reports included the mandatory information, but in $32 \%$ of them it was found to be incomplete. The information was incomplete in $39.2 \%$ of the private, 35.8 of the $\mathrm{MOH}$, and $17.3 \%$ of 
Table 1. Auditing Measures, Results and Distribution Throughout Institutions

\begin{tabular}{|c|c|c|c|c|}
\hline \multirow[t]{2}{*}{ Auditing Measures } & \multicolumn{3}{|c|}{ Type of Institution } & \multirow[t]{2}{*}{ P Value } \\
\hline & MOH Hospitals & University Hospitals & Private Hospitals & \\
\hline Number of audited units & 82 & 36 & 47 & \\
\hline Number of MMG evaluated & 835 & 367 & 435 & \\
\hline Age of MMG machines, (\%) & & & & $\mathrm{P}<0.001$ \\
\hline 0 - 5 years & 66 & 46.1 & 47.7 & \\
\hline $5-10$ years & 28.8 & 32.9 & 30.2 & \\
\hline 10 years over & 5.25 & 21 & 22.1 & \\
\hline Propriety of the machines, (\%) & & & & $\mathrm{P}<0.001$ \\
\hline Owner & 67.6 & 91.4 & 89.4 & \\
\hline Procurement & 32.4 & 8.6 & 10.6 & \\
\hline Time of prior MMG, (\%) & & & & $\mathrm{P}<0.001$ \\
\hline Less than 1 year & 64.8 & 32.6 & 68.5 & \\
\hline More than 1 year & 35.2 & 67.4 & 31.5 & \\
\hline MMG image quality, (\%) & & & & $\mathrm{P}<0.001$ \\
\hline Appropriate & 42.2 & 75.2 & 20.9 & \\
\hline Inappropriate & 57.6 & 24.8 & 79.1 & \\
\hline Mandatory information in the MMG report, (\%) & & & & $\mathrm{P}<0.001$ \\
\hline Appropriate & 64.2 & 82.7 & 60.8 & \\
\hline Inappropriate & 35.8 & 17.3 & 39.2 & \\
\hline MMG report quality, (\%) & & & & $P=0.002$ \\
\hline Appropriate & 36.2 & 50.4 & 38.4 & \\
\hline Inappropriate & 63.8 & 49.6 & 61.6 & \\
\hline
\end{tabular}

Abbreviations: MMG, mammography; MOH, Ministry of Health

Table 2. Deficiencies Found in Mammographic Image Quality

\begin{tabular}{|lc}
\hline Category & $\begin{array}{c}\text { Failures in Total Number of } \\
\text { Mammograms Evaluated, (\%) }\end{array}$ \\
\hline Positioning & 42.2 \\
\hline Contrast-density & 18.9 \\
\hline Artifacts & 15.8 \\
\hline Labeling & 9.3 \\
\hline Compression & 7.2 \\
\hline Patients' cooperation & 2.9 \\
\hline Viewing/CD technical problems & 1.9 \\
\hline Bucky problems & 1.4 \\
\hline
\end{tabular}

${ }^{\mathrm{a}}$ More than one deficiency stated.

the university hospitals reports, with a significant difference favoring the university hospitals $(\mathrm{P}<0.001)$. In most of the reports, the missing parts were information on the patient (67.2\%) or information about the institution where the examination was performed (57.5\%).

Mammographic report quality was also evaluated. The reports in the study group were found to be inadequate in $59.2 \%$ of the cases. The reason for the mammographic examination was not identified in $55.4 \%$ of the reports, and the positions taken were not identified in $35.9 \%$ of the reports. The results or recommendations were not listed in $25.2 \%$ of the reports.

\section{Discussion}

Mammographic screening effectiveness is directly related to the quality and performance of the equipment, materials, and procedures employed $(13,14)$. To assess quality, guidelines and accreditation programs have been established in various countries $(9,11,12)$. According to the results of our study, in $56.1 \%$ of the cases the mammographic 
image quality was not in compliance with the Turkish standards. A recent study also showed high percentages of poor quality, which mostly resulted from patient positioning (15). Moon et al., (16) reported that $36.3 \%$ of the mammograms examined in their study had important imagerelated deficiencies that might have led to serious errors in patient management. Bassett el al. (17) reviewed clinical images from 2,341 mammography units in the US. In their study $44 \%$ of the sites failed the clinical image evaluation process; the most frequent reason for failure was positioning (20\%), followed by exposure (15\%). The deficiencies in our study were similar. Although in our study poor positioning caused the most failures (42.2\%), the proportion was much more higher than in Basset and colleagues' report. However, Basset et al. (17) evaluated the images of units that participated in the US accreditation program. On contrary, our study did not consider accreditation when choosing or evaluating the units. This difference reveals the importance of unit accreditation. Moreover, since the most important finding and problem in our study, and in the other published studies, is patient positioning, we suggest more mandatory training of radiologic technologists.

Furthermore, there was a significant difference between private, university, and $\mathrm{MOH}$ hospitals in terms of mammographic image quality. We found that university hospitals presented better images, followed by MOH hospitals. The worst images were received from private clinics. We believe that there is a better awareness of quality in university hospitals and $\mathrm{MOH}$ hospitals. Previous scholars reported that university hospitals were significantly better than all other mammography units in overall image quality, and suggested that better positioning practices are found in university hospitals. Moon et al. (16) reported that deficiencies were lower in university hospitals than in the other clinics. On the other hand, Brnic et al. (18), Moon et al. (16), and Gwak et al. (19) also showed a lack of quality in private clinics. We suggest that these private enterprises lack quality and need to be controlled better by regulations.

We found similar results in terms of mammographic report quality, where $59.2 \%$ of the reports received were insufficient. In $55.4 \%$ of the reports the reason for the examination, which should be included according to ACR standards, was not mentioned (Table 2). Moreover, results and recommendations were not mentioned in $25.2 \%$ of reports. The distribution throughout the institutions was similar to the mammographic image quality findings, in that university hospitals had the best results, followed by MOH hospitals and private clinics. Therefore, it is essential to provide quality control and training of radiologists in all hospitals.

Regarding the type of the machines, only $21.4 \%$ were full field digital machines, while $46.6 \%$ were analog machines with CR systems producing digital images. Gurdemir and Aribal (15) reported that CR machines that were not suitable for breast imaging were used frequently. Although our study did not aim to investigate the quality of the machines, we believe that this may be one of the reasons for the lack of quality in mammographic images.

One of the major limitations of this study is the lack of physical quality control findings regarding the machines. The quality of the examinations depends on these routine controls $(9,10)$. As we do not have this data, we do not present a quantitative measurement on quality. The second limitation is the lack of phantom images. Only $2.9 \%$ of the units sent daily phantom images to check. Therefore, it was not possible to evaluate the technical quality of the devices. Since the technical quality of the devices have direct effects on image quality, we do know how much image quality has been affected by this factor. The third limitation is the subjective nature of the evaluation criteria. Although the images were examined by experienced breast radiologists, rating methods were dependent on each individual's understanding of the scale, knowledge, and experience. Therefore, future studies should develop more detailed and objective criteria to allow for stronger conclusions.

In conclusion, this study identified several problems encountered in Turkey in terms of quality management in breast imaging: 1) Lack of mammographic image quality, 2) inappropriate reporting, 3) and significant deficiencies in private hospitals. Therefore, we suggest that more time and resources should be spent to train both radiologists and radiologic technicians to implement image and report quality in their units. Moreover, our study emphasized the importance of the accreditation of the units.

\section{Acknowledgments}

We would like to acknowledge and thank all of the auditors and reporters listed below for their hard work throughout the study. Auditors: Adnan Kabaalioglu, Artur Salmaslioglu, Ayse Murat Aydin, Ayse Nurdan Barça, Aysegul Ozdemir, Aysenur Oktay, Dilek Emlik, Ebru Dusunceli Atman, Eda Elverici, Emel Alimoglu, Fahrettin Kiliç, Figen Demirkazik, Filiz Yenicesu, Fusun Taskin, Gulden Acunas, Gulnur Erdem, Hatice Gumus, Irmak Durur Subasi, Isil Bilgen, Ibrahim Somuncu, Iclal Isiklar, Kagan Çeken, Meltem Çetin, Meltem Gulsun Akpinar, Nermin Tunçbilek, Nuran A.Sabir Akkoyunlu, Pelin Oztekin, Pinar Balci, Serap Dogan, Serap Gultekin, Sibel Kul, and Zehra Hilal Adibelli. Reporters: Aysun Yildirim, Necvan Tokmak. 


\section{Footnotes}

Authors' Contribution: Design and conduct of the study, collection, management, and analysis of the data, development of the protocol, and preparation of the manuscript, Arzu Ozsoy, Levent Araz, Erkin Aribal, Nevra Elmas; design and conduct of the study, analysis of the data, and development of the protocol, Merter Bora Erdogdu, Aydin Sari, Irfan Sencan.

Funding/Support: This work was financially supported by the ministry of health of Turkey.

\section{References}

1. Luke C, Priest K, Roder D. Changes in incidence of in situ and invasive breast cancer by histology type following mammography screening. Asian Pac J Cancer Prev. 2006;7(1):69-74. [PubMed: 16629519].

2. World Health Organization. WHO Position Paper on Mammography Screening. Geneva: World Health Organization; 2014.

3. Eklund GW, Cardenosa G, Parsons W. Assessing adequacy of mammographic image quality. Radiology. 1994;190(2):297-307. doi:10.1148/radiology.190.2.8284372. [PubMed: 8284372].

4. Reis C, Pascoal A, Sakellaris T, Koutalonis M. Quality assurance and quality control in mammography: a review of available guidance worldwide. Insights Imaging. 2013;4(5):539-53. doi: 10.1007/s13244-0130269-1. [PubMed: 23912879].

5. Ciraj-Bjelac O, Avramova-Cholakova S, Beganovic A, Economides S, Faj D, Gershan V, et al. Image quality and dose in mammography in 17 countries in Africa, Asia and Eastern Europe: results from IAEA projects. EurJRadiol. 2012;81(9):2161-8. doi: 10.1016/j.ejrad.2011.05.026. [PubMed: 21665395].

6. Baskan S, Atahan K, Arıbal E, Ozaydın N, Balci P, Yavuz E. Screening and diagnosis in breast cancer (Istanbul breast cancer consensus conference 2010). J Breast Health. 2012;8:100-25.

7. Taplin SH, Rutter CM, Finder C, Mandelson MT, Houn F, White E. Screening mammography: clinical image quality and the risk of interval breast cancer. AJR Am J Roentgenol. 2002;178(4):797-803. doi: 10.2214/ajr.178.4.1780797. [PubMed: 11906848].

8. ACR (American College of Radiology) . Mammography Quality Control Manual. 1 ed. Reston: American College of Radiology; 1999.
9. de Wolf CJM, Perry NM. European guidelines for quality assurance in mammography screening. Luxembourg: European Communities; 1996. pp. 7-218.

10. LiY, Poulos A, McLean D, Rickard M. A review of methods of clinical image quality evaluation in mammography. Eur J Radiol. 2010;74(3):12231. doi:10.1016/j.ejrad.2009.04.069. [PubMed: 19482454].

11. TRD (Turkish Society of Radiology) Breast Study Group . Mammograpy quality standards. Ankara: Turkish Society of Radiology; 2005. pp. 1-65.

12. Destouet JM, Bassett LW, Yaffe MJ, Butler PF, Wilcox PA. The ACR's Mammography Accreditation Program: ten years of experience since MQSA. J Am Coll Radiol. 2005;2(7):585-94. doi: 10.1016/j.jacr.2004.12.005. [PubMed:17411883].

13. Hendrick RE, Helvie MA. United States Preventive Services Task Force screening mammography recommendations: science ignored. $A J R$ Am J Roentgenol. 2011;196(2):112-6. doi: 10.2214/AJR.10.5609. [PubMed: 21257850].

14. Hwang YS, Tsai HY, Chen CC, Tsay PK, Pan HB, Hsu GC, et al. Effects of quality assurance regulatory enforcement on performance of mammography systems: evidence from large-scale surveys in Taiwan. AJR Am J Roentgenol. 2013;201(2):307-12. doi: 10.2214/AJR.12.9614. [PubMed: 23883245].

15. Gurdemir B, Aribal E. Assessment of mammography quality in Istanbul. Diagn Interv Radiol. 2012;18(5):468-72. doi: 10.4261/13053825.DIR.5400-11.1. [PubMed: 22801869].

16. Moon WK, Kim TJ, Cha JH, Cho KS, Choi EW, Lee YJ, et al. Clinical image evaluation of mammograms: a national survey. J Korean Radiol Soc. 2003;49(6):507-11.

17. Bassett LW, Farria DM, Bansal S, Farquhar MA, Wilcox PA, Feig SA. Reasons for failure of a mammography unit at clinical image review in the American College of Radiology Mammography Accreditation Program. Radiology. 2000;215(3):698-702. doi: 10.1148/radiology.215.3.roojn32698. [PubMed:10831687].

18. Brnic Z, Blaskovic D, Klasic B, Ramac JP, Flegaric-Bradic M, Stimac D, et al. Image quality of mammography in Croatian nationwide screening program: comparison between various types of facilities. Eur J Radiol. 2012;81(4):478-85. doi: 10.1016/j.ejrad.2011.06.020. [PubMed: 21715115].

19. Gwak YJ, Kim HJ, Kwak JY, Son EJ, Ko KH, Lee JH, et al. Clinical image evaluation of film mammograms in Korea: comparison with the ACR standard. Korean J Radiol. 2013;14(5):701-10. doi: 10.3348/kjr.2013.14.5.701. [PubMed: 24043961]. 